\title{
Dextrose Prolotherapy for Muscle, Tendon and Ligament Injury or Pathology: A Systematic Review
}

\author{
Sholahuddin Rhatomy ${ }^{1^{*}}$, Evlin Margaretha ${ }^{2}$ and Rizki Rahmadian ${ }^{3}$ \\ ${ }^{1}$ Department of Orthopaedics and Traumatology, Dr. Soeradji Tirtonegoro General Hospital, Klaten, \\ Faculty of Medicine, Public Health and Nursing, Universitas Gadjah Mada, Yogyakarta, Indonesia. \\ ${ }^{2}$ Department of Anesthesiology and Intensive Care, Faculty of Medicine, Baiturrahmah University, \\ Padang, Indonesia. \\ ${ }^{3}$ Department of Orthopaedics and Traumatology, Dr. M Jamil General Hospital, Padang, Faculty of \\ Medicine, University of Andalas, Padang, Indonesia.
}

\section{Authors' contributions}

This work was carried out in collaboration among all authors. Authors SR and RR designed the study, performed the statistical analysis, wrote the protocol and wrote the first draft of the manuscript. Authors SR and EM managed the analyses of the study. Author SR managed the literature searches.

All authors read and approved the final manuscript.

Article Information

DOI: $10.9734 / A R R B / 2020 / v 35 i 1030288$ Editor(s):

(1) Dr. Md. Torequl Islam, Federal University of Piaui, Brazil.

Reviewers:

(1) Meenakumari Natarajan, National Institute of Epidemiology-(NIE-ICMR), India.

(2) Venkatesh Balaji Hange, Dr. B. R. Ambedkar University, India. Complete Peer review History: http://www.sdiarticle4.com/review-history/61771

Systematic Review Article

Received 30 July 2020

Accepted 05 October 2020

Published 17 October 2020

\section{ABSTRACT}

Background: Prolotherapy with dextrose has recently gained attention as a potential treatment for muscle, ligament or tendon pathology/injury.

Questions/Purpose: This review aimed to: 1) evaluate the main outcome of dextrose prolotherapy treatment for muscle, ligament or tendon pathology/injury; 2) determine the concentrations of dextrose and protocol of injection; and 3) assess complications or adverse effects after dextrose prolotherapy.

Methods: Four electronic databases were searched for related published articles. Articles that met the following criteria were included in this review: 1) articles on peer-reviewed level 1 to 4 studies; 2) articles published in English; 3) articles on dextrose prolotherapy study for tendon or ligament or muscle injury/pathology; and 5) articles that describe dose of dextrose. Published articles that met this inclusion criteria were included in this systematic review. 
Results: Twenty four studies fulfilled inclusion criteria,consisting of seventeen clinical studies, four animal studies and three invitro studies. Eleven studies reported there were improvement of functional outcome after dextrose prolotherapy. Three Studies reported improvement of patient satisfaction after dextroprolotherapy in supraspinatus tear, Achilles tendinopathy. And patellar tendinopathy, meniscus tear and anterior tibiofibular ligament tear. Three studies reported there are increasing of neovascularization in Achilles tendinopathy and patellar tendinopathy in animal studies, increasing of inflammatory response in animal studies and in vitro studies and increasing of cell proliferation and collagen production. Nine studies $(52 \%)$ use dextrose $25 \%$ concentration. A few adverse effects were reported and minor effect, such as discomfort Minor soreness, extreme pain, skin burns 2nd grade, hypotension, Deep Vein Thrombosis (DVT) ( patient has history DVT).

Conclusions: Dextrose Prolotherapy is a potentially effective treatment for patients with muscle, tendon or ligament tear or pathology. Efficacy in long term follow-up, as single therapy or first-line therapy cannot be determined from the current literature.

Keywords: Dextrose; prolotherapy; muscle; tendon; ligament.

\section{INTRODUCTION}

Musculoskeletal injuries are the most common cause of chronic pain and decreased body function [1]. In the United States, soft tissue trauma accounts for $45 \%$ of injuries reported in the orthopedic clinical settings. Among physically active individuals, at least $80 \%$ of musculoskeletal injuries are directly related to physical activity, and more than $85 \%$ of injuries sustained by athletes are soft tissue injuries [2]. Accordingly, effective treatment of soft tissue trauma is essential for physically active individuals and competitive athletes. Prolotherapy, sometimes abbreviated as (PrT) is a therapeutic alternative for a musculoskeletal injury or pathology $[1,2]$.

Previous study found that injection of a hypertonic sugar solution around ligaments could reduce back pain related to weakened articular ligaments. Hackett believed that the proliferant solution would stimulate the production of fibrous tissue, thereby strengthening the ligaments. He noted that the treatment provided satisfactory results immediately [3].

Prolotherapy is believed to strengthen damaged ligaments or tendons through the stimulation of fibrous tissue synthesis. Frequency of prolotherapy administration generally includes 36 times around the involved tendon and ligament attachment sites at 4-6-week intervals. The treatment response will vary according to injury severity, which determines the amount of collagen synthesis that is necessary for tissue repair. Concomitant administration of therapeutic exercise is recommended to enhance the effectiveness of the injection [4].
The most common prolotherapy used in clinical practice is dextrose. Based on previous studies, the most frequently used dextrose concentration ranges from $10 \%$ to $25 \%$. Dextrose is chosen because it is water soluble and safe to inject into many areas and can be used in large volume.

Dextrose has been accepted generally by the Food and Drug Administration United States, but not specifically for prolotherapy [5-7]. The action mechanism of dextrose works by dehydrating cells at the injection site, causing inflammation, which will attract granulocytes and macrophages and enhance the healing process [5].

There are still only a small number of studies about dextrose prolotherapy and there is no consensus on the protocol for treatment such as concentration, volume of injection, frequency of injection, or time interval for treatment of muscle, tendon and ligament injury/pathology. The aim of this systematic review was to evaluate the main outcomes and adverse effects of dextrose prolotherapy as a treatment of muscle, tendon and ligament injury/pathology and determine the most effective dose of dextrose for prolotherapy.

\section{METHODS}

\subsection{Outcomes Measure}

To assess the outcomes of dextrose prolotherapy for muscle, tendon and ligament injury, we: 1) evaluated the main outcome after dextrose prolotherapy treatment, 2) determined concentrations of dextrose and protocol of injection; and 3) assessed complications or adverse effects after dextrose prolotherapy. 


\subsection{Literature Search and Study Selection}

PubMed (Medline), Embase, Scopus, and the Cochrane library were searched from database inception until August $25^{\text {th }}, 2020$ to study about dextrose prolotherapy injection for muscle, tendon and ligament injury. The search terms: "prolotherapy" or "dextrose" and "muscle" or "ligament" or "tendon" were used.

\subsection{Eligibility Criteria}

Inclusion criteria were: 1) articles on peerreviewed level 1 to 4 studies; 2) articles published in English; 3) articles on dextrose prolotherapy study for tendon or ligament or muscle injury/pathology; and 4) articles that describe dose of dextrose. Published articles that met these inclusion criteria were included in this systematic review.

Non-English articles, duplicate articles, literature reviews, articles on studies that involve cadaveric investigation, biomechanical study, letters to editors, instructional courses, and technical notes were excluded. We also excluded articles with incomplete information on diagnosis, examination, follow-up duration, clinical postoperative outcomes, and no statistical analysis.

\subsection{Study Screening and Data Abstraction}

Two authors (S.R and R.R) independently screened study and extracted data. Disagreements were resolved by discussion between the two review authors. If no agreement could be reached, consultation with a third author was done. The reference lists of all included studies were also screened for additional articles relevant to this review.

This study included in vitro or in vivo, animal studies, case reports, case series, prospective or retrospective studies, and randomized or nonrandomized control trial studies. The data from the articles were extracted using a predesigned form which included sample size, age, intervention, concentration of dextrose, time interval, main outcome and complications or adverse effects. Raw data for continuous outcome measures were extracted at all reported follow-up times (if available), including means and standard deviations (SDs).

\subsection{Quality Assessment and Risk of Bias}

The methodological quality was evaluated using the Preferred Reporting Items for Systematic
Reviews and Meta-Analyses (PRISMA) guidelines (6). Two authors (S.R and R.R) independently performed all the assessments. Coleman Methodology Score (CMS) was used to quantify the quality of the article. The article's methodology was assessed by CMS with a total score ranging from 0 to 100 . The higher CMS score of the article, the more valid the article because it was free from biases and confounding factors [7]. To avoid bias, the included and excluded article were reviewed and re-assessed by all of the researchers, if there was any disagreement between them.

\section{RESULTS}

\subsection{Study Selection}

5,091 articles were obtained from the database literature searching and 4,229 articles were excluded based on the titles or due to duplication. A total of 862 articles were eligible for further screening. Seven-hundred-and-fortysix articles were excluded because they did not match the inclusion criteria resulting in a total of 116 articles. Ninety-two articles were excluded after full-text screening was performed. We excluded these articles due to: Dextrose prolotherapy fused other than tendon or ligament or muscle $(n=82)$, they were either technical notes, short communications, or reviews $(n=7)$, they were cadaveric, or biomechanical studies $(n=3)$. Accordingly, 24 full articles were included in this systematic qualitative review. The flow chart of article selection is shown in Fig. 1.

\subsection{Characteristics of Selected Studies}

Seven studies (28\%) were randomized control trials, seven studies (28\%) were prospective studies, two were case series, four were animal studies, and three were laboratory in vitro studies. These clinical studies included 730 patients. There were 364 male (55.4\%) and 293 female $(44.6 \%)$ patients. Three studies did not describe the gender distribution (73 patients). The average age at the time of study was 6.9 month (range, 45 days - 29 month). The average follow-up duration was 7.4 months (range, 45 days- 28 months). The clinical studies evaluated the effect of dextrose prolotherapy on supraspinatus tendon in 6 studies (35\%), Achilles tendon in 6 studies (35\%), and the other studies were done on patellar tendon, plantar fascia, anterior cruciate ligament and acromion enthesopathy. There were four animal studies that all used rats for subjects, and 2 studies focused to evaluate medial collateral ligament, 


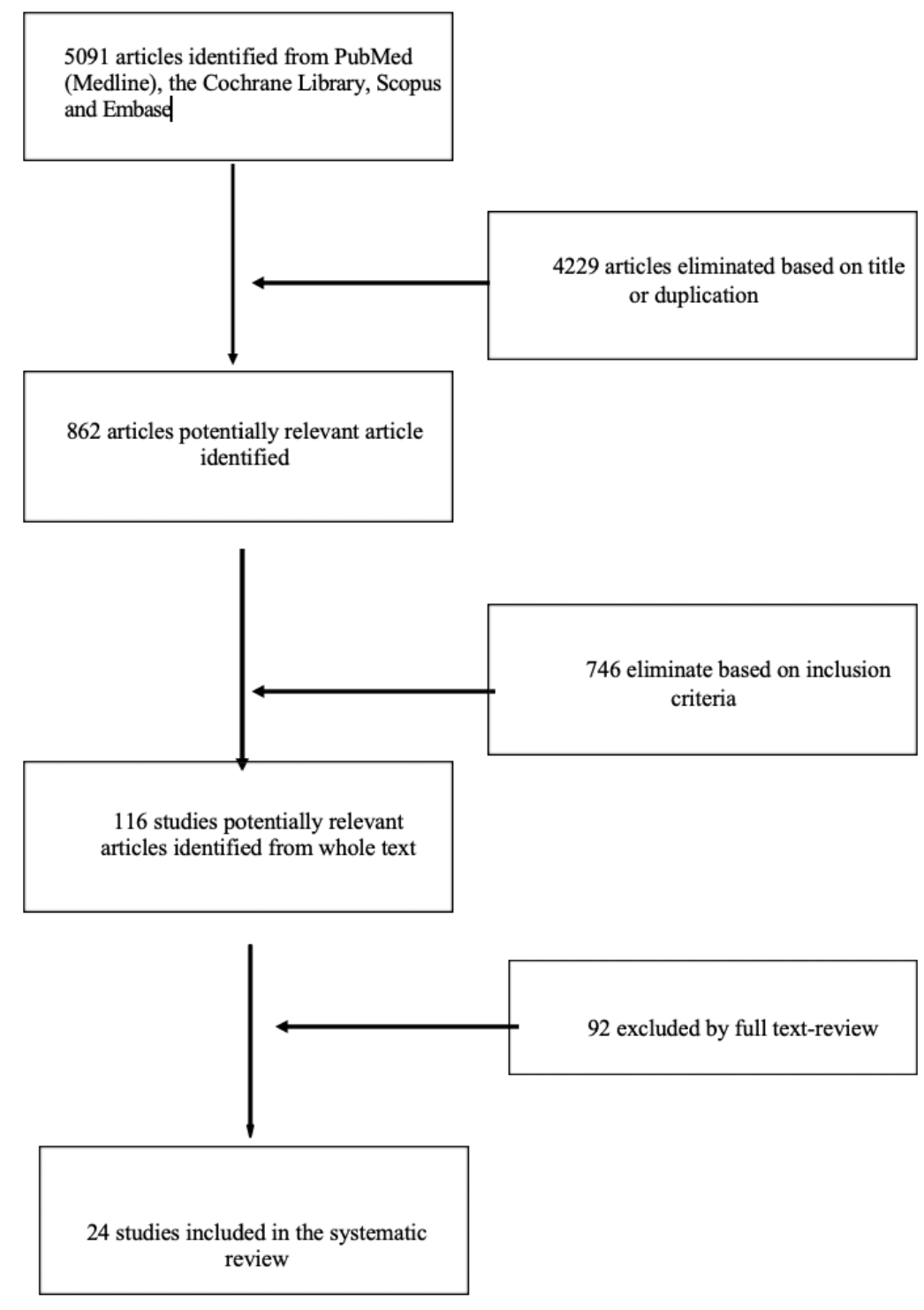

Fig. 1. Flow chart of study process selection

Achilles tendon in 1 study and gastrocnemius muscle in 1 study. Also, there were three in vitro studies that included 2 studies using human hamstring and/or Achilles tendon and adult human fibroblasts and one study used rat patellar tendon fibroblasts (Table 1).

\subsection{Main Outcomes}

\subsubsection{Pain visual analog scale score}

All of studies reported about good improvement of pain using the VAS score after dextrose prolotherapy treatment. A total of 6 studies reported improvement in supraspinatus tendon tear or pathology [8-13], 6 studies reported in Achilles tendon cases [4,14-18] and the other studies reported improvement in pain VAS score in treatment of patellar tendon, meniscus, acromion enthesopathy, anterior cruciate ligament laxity and anterior tibiofibular ligament injury [19-23].

\subsubsection{Functional outcome}

Eleven studies reported there were improvement of functional outcome after dextrose prolotherapy [9-11,13-15,18,19,21-23]. Five studies used a special scoring to evaluate the outcome. Seven et al. used the Shoulder Pain and Disability Index 
(SPADIs) and the Western Ontario Rotator Cuff (WORC) to evaluate supraspinatus tear [9], George et al. used the Disability of Arm and Shoulder (DASH) to evaluate supraspinatus tear [10], Lee et al. and Lin et al. used the Shoulder Pain and Disability Index (SPADIs) to evaluate supraspinatus tearing [11,13], and $\mathrm{Kim}$ et al. used the Foot Functional Index total to evaluate outcome in plantar fasciitis [21].

\subsubsection{Patient satisfaction}

Three studies reported improvement of patient satisfaction after dextroprolotherapy in supraspinatus tear [8], Achilles tendinopathy [15], and patellar tendinopathy, meniscus tear and anterior tibiofibular ligament tear [19].

\subsubsection{Neo vascularization}

Three studies reported there was increasing of neovascularization after dextroprolotherapy in Achilles tendinopathy $[16,17]$ and patellar tendinopathy [22].

\subsubsection{Inflammatory response}

Three studies reported there was increasing of inflammatory response after dextrose prolotherapy in vivo/animal studies $[24,25]$ and in vitro study [26].

\subsubsection{Cell proliferation}

Freeman et al. reported that there were increasing of cell proliferation and collagen production after dextrose treatment [27].

\subsection{Concentration of Dextrose and Injection Protocol}

There are nine studies (52\%) used the concentration of dextrose with $25 \%$ $[8,9,12,14,16,17,22,23,28]$ while three studies each used concentrations with $20 \%[11,15,18]$ or $15 \%$ [19-21]. The other two studies used concentrations of $10 \%$ [23] and $16.5 \%$ [13]. Most of study (15 studies/88\%) reported dextrose mixed with lidocaine, and only one study used a mix with saline [8] or marcaine [28].

Five studies (29.4\%) performed prolotherapy monthly $[8,18,19,20,23]$ and four studies performed it with only a single injection [1012,14]. Four studies performed prolotherapy every 1 week or 2 weeks $[9,13,15,21]$. Additionally, three studies performed it every 6 weeks $[16,17,22]$.

Table 1. Overview of clinical study

\begin{tabular}{lll}
\hline No & Author, year, country & Type of study \\
\hline 1 & Bertrand et al., 2015, Canada [8] & Randomized controlled Trial \\
2 & Seven et al., 2017, Turkey [9] & Randomized controlled Trial \\
3 & George et al., 2018, Malaysia [10] & Randomized controlled Trial \\
4 & Lin et al., 2018,Taiwan [11] & Randomized controlled Trial \\
5 & Cole et al., 2017, Australia [12] & Randomized Controlled Trial \\
6 & Buchanan et al., 2016, USA [14] & Prospective study \\
7 & Lyftogt et al., 2005, New Zealand [15] & Prospective study \\
8 & Maxwell et al., 2007, Canada [16] & Prospective study \\
9 & Ryan et al., 2010, Canada [17] & Prospective study \\
10 & Fullerton et al., 2008, USA [19] & Case series \\
11 & Hsieh et al., 2018, Taiwan [20] & Prospective study \\
12 & Kim et al., 2014, Korea [21] & Randomized Controlled Trial \\
13 & Lee et al., 2015, Korea [13] & Retrospective case-control study \\
14 & Chan et al., 2017, UK [28] & Case series \\
15 & Ryan et al., 2011, USA [22] & Prospective study \\
16 & Yelland et al., 2009, Australia [18] & Randomized Controlled Trial \\
17 & Reeves et al., 2003, USA [23] & Prospective study \\
18 & Jensen, et al., 2008, USA [24] & Animal Study \\
19 & Jensen, et al., 2008, USA [29] & Animal Study \\
20 & Martins et al., 2011, Brazil [25] & Animal Study \\
21 & Tsai et al., 2018, Taiwan [30] & Animal Study \\
22 & Freeman et al., 2011, USA [27] & In vitro Study \\
23 & Güran et al., 2018, Turkey [31] & In vitro Study \\
24 & Ekwueme et al., 2017, USA [26] & In vitro Study \\
\hline & & \\
\hline
\end{tabular}


Table 2. Clinical studies results

\begin{tabular}{|c|c|c|c|c|c|c|c|c|c|}
\hline No & Author & Site & $\begin{array}{l}\text { Sample size } \\
\text { (pts) and } \\
\text { Sex }(M: F)\end{array}$ & $\begin{array}{l}\text { Age, years } \\
\text { (SD/range) }\end{array}$ & Intervention & Dose of dextrose & Results & $\begin{array}{l}\text { Follow- } \\
\text { up }\end{array}$ & $\begin{array}{l}\text { Complication } \\
\text { reported }\end{array}$ \\
\hline 1 & $\begin{array}{l}\text { Bertrand } \\
\text { et al. [8] }\end{array}$ & $\begin{array}{l}\text { Supraspinatus } \\
\text { tendinosis/tear }\end{array}$ & $\begin{array}{l}73 \\
46: 27\end{array}$ & $51(13)$ & $\begin{array}{l}\text { Three monthly } \\
\text { injections with } \\
\text { dextrose, injection } \\
\text { on entheses with } \\
\text { saline or above } \\
\text { entheses with } \\
\text { saline. } \\
\text { All solutions } \\
\text { included } 0.1 \% \\
\text { lidocaine. }\end{array}$ & $\begin{array}{l}25 \% \text { dextrose }+ \\
0.1 \% \\
\text { lidocaine/saline }\end{array}$ & $\begin{array}{l}\text { - } 59 \% \text { of dextrose } \\
\text { patient showed } \geq 2.8 \\
\text { decrease of pain } \\
\text { compared with Enthesis- } \\
\text { Saline }(37 \% ; P=.088) \text { and } \\
\text { Superficial-Saline }(27 \% \text {; } \\
p=.017) \text {. } \\
\text { - Dextrose group } \\
\text { satisfaction was } 6.7 \pm 3.2 \\
\text { compared with Enthesis- } \\
\text { Saline }(4.7 \pm 4.1 ; p=.079) \\
\text { and Superficial-Saline } \\
(3.9 \pm 3.1 ; p=.003) \text {. }\end{array}$ & 9 month & $\begin{array}{l}\text { Discomfort } \\
\text { and Minor } \\
\text { soreness }\end{array}$ \\
\hline 2 & $\begin{array}{l}\text { Seven et } \\
\text { al. [9] }\end{array}$ & $\begin{array}{l}\text { Chronic rotator } \\
\text { cuff lesions }\end{array}$ & $\begin{array}{l}101 \\
42: 59\end{array}$ & $51(12)$ & $\begin{array}{l}\text { Two groups: } \\
\text { - control group; } \\
\text { exercise } \\
\text { - prolotherapy } \\
\text { group; dextrose } \\
\text { injection }\end{array}$ & $\begin{array}{l}4 \mathrm{ml} ; \text { a mixture } \\
3.6 \mathrm{~mL} \text { of } 25 \% \\
\text { dextrose and } \\
0.4 \mathrm{~mL} \text { lidocaine }\end{array}$ & $\begin{array}{l}\text { A significant difference in : } \\
-\quad \text { VAS at baseline, } \\
\text { weeks } 3,6 \text {, and 12, and } \\
\text { last follow-up. } \\
-\quad \quad \text { SPADIs and } \\
\text { WORC at weeks } 6 \text { and } 12 \\
\text { and the last follow-up. } \\
\text { - Shoulder } \\
\text { abduction and flexion at } \\
\text { week } 12 \text { and last follow- } \\
\text { up, and in internal rotation } \\
\text { at last follow-up. } \\
\text { No significant in external } \\
\text { rotation at any follow-up } \\
\text { period. } \\
\text { Prolotherapy group : } \\
\text { 92.9\% patient reported } \\
\text { excellent or good } \\
\text { outcomes }\end{array}$ & $\begin{array}{l}12 \\
\text { month }\end{array}$ & $\begin{array}{l}\text { Extreme pain } \\
\text { prolotherapy } \\
\text { group (3 } \\
\text { patients). } \\
\text { Skin burns (1 } \\
\text { patient) } \\
\text { and } \\
\text { Hypotension } \\
\text { (1 patient) }\end{array}$ \\
\hline
\end{tabular}


Rhatomy et al.; ARRB, 35(10): 43-62, 2020; Article no.ARRB.61771

\begin{tabular}{|c|c|c|c|c|c|c|c|c|c|}
\hline No & Author & Site & $\begin{array}{l}\text { Sample size } \\
\text { (pts) and } \\
\text { Sex (M:F) }\end{array}$ & $\begin{array}{l}\text { Age, years } \\
\text { (SD/range) }\end{array}$ & Intervention & Dose of dextrose & Results & $\begin{array}{l}\text { Follow- } \\
\text { up }\end{array}$ & $\begin{array}{l}\text { Complication } \\
\text { reported }\end{array}$ \\
\hline 3 & $\begin{array}{l}\text { George et } \\
\text { al. [10] }\end{array}$ & $\begin{array}{l}\text { Supraspinatus } \\
\text { Tendinosis }\end{array}$ & $\begin{array}{l}12 \\
N R\end{array}$ & 59 (NR) & $\begin{array}{l}\text { Prolotherapy } \\
\text { group: dextrose } \\
\text { injection } \\
\text { Control group: } \\
\text { Standard } \\
\text { physiotherapy }\end{array}$ & $\begin{array}{l}0,5-1 \mathrm{ml}(12.5 \% \\
\text { dextrose, } 0.5 \% \\
\text { lignocaine) }\end{array}$ & $\begin{array}{l}\text { 1. 20-degree improvement } \\
\text { in abduction ROM ( } p= \\
0.03 \text { ) } \\
\text { 2. Decrease in } \\
\text { DASH pain score of } 2 \text { or } \\
\text { greater, compared to } \\
\text { controls. (not statistical } \\
\text { significance). } \\
\text { 3. Sleep score } \\
\text { improvement (significant } \\
\text { statistically different). } \\
\text { 4. Dextrose group } \\
\text { showed improvement in } \\
\text { echogenicity within the } \\
\text { area of tendinosis }\end{array}$ & $\begin{array}{l}12 \\
\text { Week }\end{array}$ & None \\
\hline 4 & $\begin{array}{l}\text { Lin et } \\
\text { al.[11] }\end{array}$ & $\begin{array}{l}\text { Chronic } \\
\text { Supraspinatus } \\
\text { Tendinopathy }\end{array}$ & $\begin{array}{l}31 \\
19: 12\end{array}$ & $49(6)$ & $\begin{array}{ll}\text { - } & \text { Intervention } \\
& \text { group: } \\
\text { dextrose } 20 \% \\
\text { injection } \\
\text { - Control group: } \\
\text { 5\% normal } \\
\text { saline injection }\end{array}$ & $\begin{array}{l}5 \mathrm{ml} \text { of } 20 \% \\
\text { Dextrose } \\
\text { solution }(4 \mathrm{ml} \\
50 \% \text { dextrose }+1 \\
\mathrm{ml} \text { normal } \\
\text { saline) }\end{array}$ & $\begin{array}{l}\text { - A significant } \\
\text { improvement in the VAS } \\
(p=0.001), \text { SPADI scores } \\
(p=0.017), \text { shoulder } \\
\text { AROM of flexion } \\
(p=0.039) \text {, and abduction } \\
(p=0.043) \\
-\quad \text { No differences in } \\
\text { the histograms and } \\
\text { morphological changes } \\
\text { (thickness) before and } \\
\text { after injection in both } \\
\text { groups. }\end{array}$ & 6 Week & None \\
\hline 5 & $\begin{array}{l}\text { Cole et } \\
\text { al.[12] }\end{array}$ & $\begin{array}{l}\text { Supraspinatus } \\
\text { Tendinopathy }\end{array}$ & $\begin{array}{l}36 \\
27: 9\end{array}$ & $51(16)$ & $\begin{array}{l}\text { - Prolotherapy } \\
\text { group } \\
\text { - Corticosteroid } \\
\text { group }\end{array}$ & $\begin{array}{l}1 \mathrm{~mL} \text { of } 50 \% \\
\text { glucose }(25 \mathrm{~g} / 50 \\
\mathrm{mL}) \\
\text { (Glucose } 50 \%) \\
\text { and } 1 \mathrm{~mL} \text { of } 1 \% \\
\text { lignocaine }\end{array}$ & $\begin{array}{l}\text { - Pain with } \\
\text { overhead activities was } \\
\text { significantly reduced at } \\
\text { the 3-month follow-up in } \\
\text { the prolotherapy group } \\
\text { and at the 6-month follow- }\end{array}$ & 6 Month & None \\
\hline
\end{tabular}


Rhatomy et al.; ARRB, 35(10): 43-62, 2020; Article no.ARRB.61771

\begin{tabular}{|c|c|c|c|c|c|c|c|c|c|}
\hline No & Author & Site & $\begin{array}{l}\text { Sample size } \\
\text { (pts) and } \\
\text { Sex (M:F) }\end{array}$ & $\begin{array}{l}\text { Age, years } \\
\text { (SD/range) }\end{array}$ & Intervention & Dose of dextrose & Results & $\begin{array}{l}\text { Follow- } \\
\text { up }\end{array}$ & $\begin{array}{l}\text { Complication } \\
\text { reported }\end{array}$ \\
\hline & & & & & & $\begin{array}{l}\text { hydrochloride } \\
=25 \% \text { glucose } \\
\text { prolotherapy } \\
\text { solution. }\end{array}$ & $\begin{array}{l}\text { up for both the } \\
\text { prolotherapy and } \\
\text { corticosteroid groups. }\end{array}$ & & \\
\hline \multirow[t]{5}{*}{6} & \multirow[t]{5}{*}{$\begin{array}{l}\text { Buchanan } \\
\text { et al.[14] }\end{array}$} & \multirow[t]{5}{*}{$\begin{array}{l}\text { insertional } \\
\text { Achilles calcific } \\
\text { tendinosis }\end{array}$} & \multirow[t]{5}{*}{$\begin{array}{l}10 \\
7: 3\end{array}$} & \multirow[t]{5}{*}{47 (NR) } & \multirow[t]{5}{*}{$\begin{array}{l}\text { Dextrose injection } \\
\text { of the distal } \\
\text { calcaneal tendon }\end{array}$} & \multirow{5}{*}{$\begin{array}{l}2 \mathrm{~mL} \text { mixture of } \\
1 \mathrm{~mL} \text { of } 1 \% \\
\text { lidocaine and } 1 \\
\mathrm{~mL} \text { of } 50 \% \\
\text { dextrose is } \\
\text { placed in a } \\
\text { syringe }\end{array}$} & $\begin{array}{l}\text { - Five patients } \\
\text { reported drastic pain relief } \\
\text { and return to normal gait } \\
\text { and sports activity within } 8 \\
\text { weeks. }\end{array}$ & \multirow[t]{5}{*}{ NR } & \multirow[t]{5}{*}{ None } \\
\hline & & & & & & & $\begin{array}{l}\text { - The average pain } \\
\text { level by VAS at rest was } \\
1 / 10 \text { with two patients } \\
\text { reporting complete pain } \\
\text { relief at rest. }\end{array}$ & & \\
\hline & & & & & & & $\begin{array}{l}\text { The average pain } \\
\text { level by VAS with sport } \\
\text { activity was reported as a } \\
3 / 10 \text {. }\end{array}$ & & \\
\hline & & & & & & & $\begin{array}{l}\text { The average } \\
\text { VISA-A score was } 84, \\
\text { indicating a sizeable } \\
\text { clinical improvement in } \\
\text { pain and function. }\end{array}$ & & \\
\hline & & & & & & & $\begin{array}{l}\text { - } \quad \text { All patients no } \\
\text { recurrence of previous } \\
\text { pain levels and symptoms. }\end{array}$ & & \\
\hline \multirow[t]{2}{*}{7} & \multirow[t]{2}{*}{$\begin{array}{l}\text { Lyftogt et } \\
\text { al. [15] }\end{array}$} & \multirow[t]{2}{*}{$\begin{array}{l}\text { Achilles } \\
\text { tendinopathy }\end{array}$} & \multirow[t]{2}{*}{$\begin{array}{l}16 \text { pts (19 } \\
\text { Achilles } \\
\text { Tendinopathie } \\
\text { s) } \\
12: 4\end{array}$} & \multirow[t]{2}{*}{$\begin{array}{l}48 \text { (range } \\
37-59)\end{array}$} & \multirow[t]{2}{*}{$\begin{array}{l}\text { Injection with } 20 \% \\
\text { dextrose and } 0.1 \% \\
\text { lignocaine }\end{array}$} & \multirow[t]{2}{*}{$\begin{array}{l}1 \mathrm{ml} \text { of } \\
\text { prolotherapy } \\
\text { diluent } \\
\text { consisting of } \\
\text { dextrose } 20 \%+ \\
\text { lignocaine } 0.1 \%\end{array}$} & $\begin{array}{l}\text { - Fourteen patients } \\
\text { were satisfied with the } \\
\text { results of the treatment } \\
\text { and returned to pre-injury } \\
\text { levels of activity. }\end{array}$ & \multirow[t]{2}{*}{$\begin{array}{l}12 \\
\text { Month }\end{array}$} & \multirow[t]{2}{*}{ None } \\
\hline & & & & & & & $\begin{array}{l}\text { - One patient was } \\
\text { referred for surgery. }\end{array}$ & & \\
\hline
\end{tabular}


Rhatomy et al.; ARRB, 35(10): 43-62, 2020; Article no.ARRB.61771

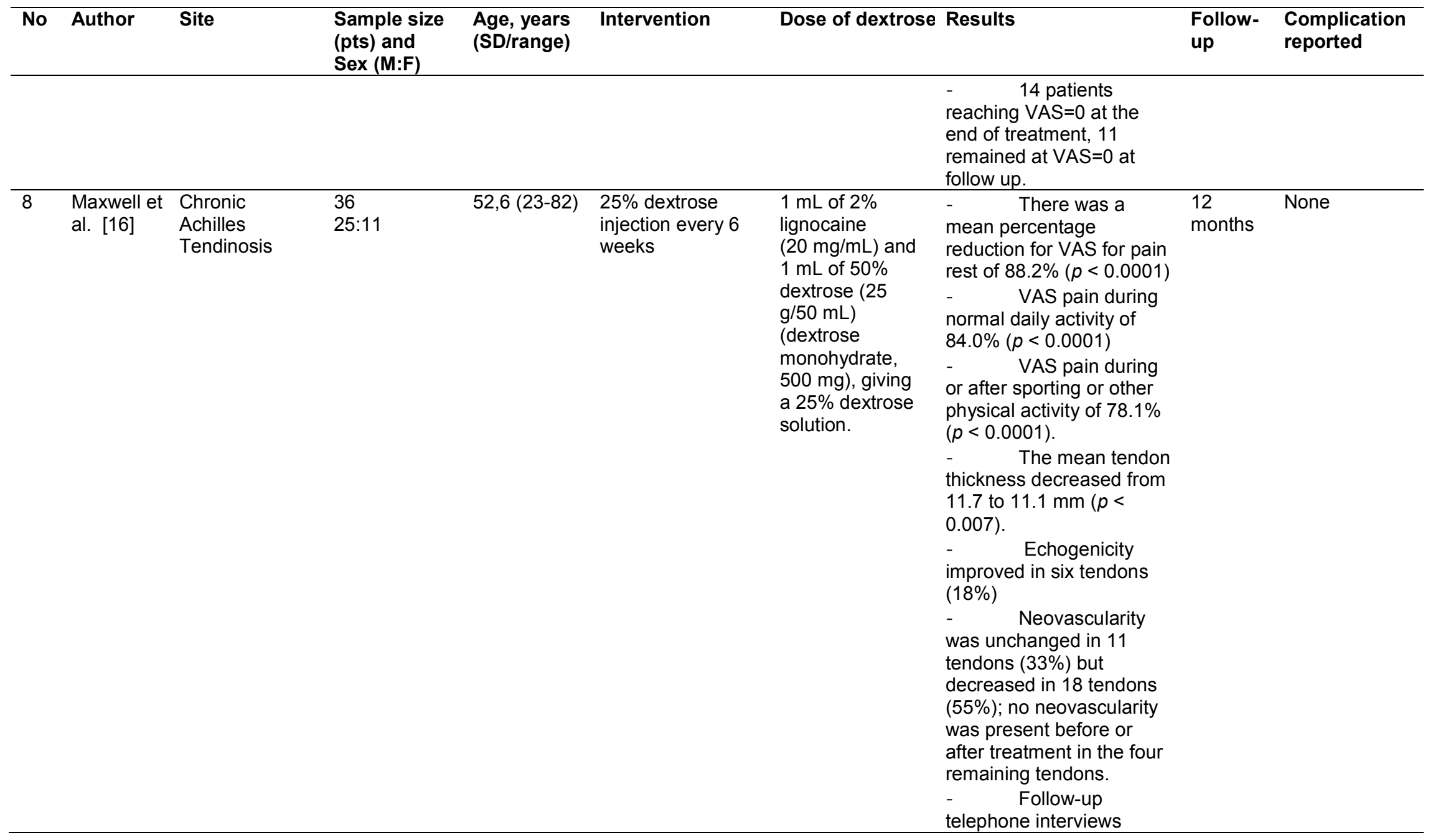


Rhatomy et al.; ARRB, 35(10): 43-62, 2020; Article no.ARRB.61771

\begin{tabular}{|c|c|c|c|c|c|c|c|c|c|}
\hline No & Author & Site & $\begin{array}{l}\text { Sample size } \\
\text { (pts) and } \\
\text { Sex (M:F) }\end{array}$ & $\begin{array}{l}\text { Age, years } \\
\text { (SD/range) }\end{array}$ & Intervention & Dose of dextrose & Results & $\begin{array}{l}\text { Follow- } \\
\text { up }\end{array}$ & $\begin{array}{l}\text { Complication } \\
\text { reported }\end{array}$ \\
\hline & & & & & & & $\begin{array}{l}\text { revealed that } 20 \text { patients } \\
\text { were still asymptomatic, } \\
\text { nine patients had mild } \\
\text { symptoms, and one } \\
\text { patient had moderate } \\
\text { symptoms. }\end{array}$ & & \\
\hline \multirow[t]{2}{*}{9} & $\begin{array}{l}\text { Ryan et } \\
\text { al. [21] }\end{array}$ & $\begin{array}{l}\text { Chronic } \\
\text { Achilles } \\
\text { Tendinosis }\end{array}$ & $\begin{array}{l}99 \text { pts (108 } \\
\text { tendons) } \\
58: 41\end{array}$ & $54.0 \pm 10.8$ & $\begin{array}{l}\text { Less than } 0.5 \mathrm{~mL} \\
\text { was injected at } \\
\text { any one site. }\end{array}$ & $\begin{array}{l}1 \mathrm{~mL} \text { of } 2 \% \\
\text { lignocaine }(20 \\
\mathrm{mg} / \mathrm{mL}) \text { and } 1 \\
\mathrm{~mL} \text { of } 50 \% \\
\text { dextrose } \\
(25 \mathrm{~g} / 50 \mathrm{~mL}) \\
\text { (dextrose } \\
\text { monohydrate } \\
500 \mathrm{mg}) \text { giving } \\
\text { a } 25 \% \text { dextrose } \\
\text { solution. }\end{array}$ & $\begin{array}{l}\text { - There was a } \\
\text { significant improvement in } \\
\text { pain scores for both } \\
\text { midportion (rest: } 34.1 \pm \\
27.7-3.3 \pm 7.4 \text {, activities } \\
\text { of daily living (ADL): } 50.2 \\
\pm 25.6-9.5 \pm 16.2 \text {, and } \\
\text { sport: } 70.7 \pm 23.3-16.7 \pm \\
22.0 \text { ) and insertional (rest: } \\
33.0 \pm 26.5-2.7 \pm 6.0, \\
\text { ADL: } 51.3 \pm 25.4-10.0 \pm \\
16.3 \text {, and sport: } 69.6 \pm \\
24.5-17.7 \pm 29.1 \text { ) }\end{array}$ & $\begin{array}{l}28.6 \\
\text { months }\end{array}$ & None \\
\hline & & & & & & & $\begin{array}{l}\text { - There were } \\
\text { reductions in the size and } \\
\text { severity of hypoechoic } \\
\text { regions and improvements } \\
\text { in neovascularity. }\end{array}$ & & \\
\hline 10 & $\begin{array}{l}\text { Fullerton, } \\
\text { BD [13] }\end{array}$ & $\begin{array}{l}\text { Patellar } \\
\text { tendinopathy, } \\
\text { anterior } \\
\text { talofibular } \\
\text { ligament } \\
\text { sprain, medial } \\
\text { meniscus tear }\end{array}$ & $\begin{array}{l}3 \\
1: 2\end{array}$ & 36,6 & $\begin{array}{l}\text { Injection dextrose } \\
\text { at pathologic site }\end{array}$ & $\begin{array}{l}(15 \% \\
\text { dextrose/0.3\% } \\
\text { lidocaine })\end{array}$ & $\begin{array}{l}\text { Good clinical and } \\
\text { sonography and MRI } \\
\text { outcome }\end{array}$ & $\begin{array}{l}\text { More } \\
\text { than } 1 \\
\text { year }\end{array}$ & None \\
\hline 11 & $\begin{array}{l}\text { Hsieh PC } \\
\text { et al. [28] }\end{array}$ & $\begin{array}{l}\text { Acromial } \\
\text { Enthesopathy }\end{array}$ & $\begin{array}{l}31 \\
10: 21\end{array}$ & $57.4 \pm 10.4$ & $\begin{array}{l}\text { Injecting } 10 \mathrm{~mL} \text { of } \\
\text { a } 15 \% \text { dextrose } \\
\text { solution into }\end{array}$ & $\begin{array}{l}50 \% \text { dextrose } \\
\text { diluted to a final } \\
\text { concentration of }\end{array}$ & $\begin{array}{l}\text { - Twenty of the } 31 \\
\text { patients reported pain } \\
\text { reduction }\end{array}$ & $\begin{array}{l}61.8 \\
\text { days }\end{array}$ & None \\
\hline
\end{tabular}


Rhatomy et al.; ARRB, 35(10): 43-62, 2020; Article no.ARRB.61771

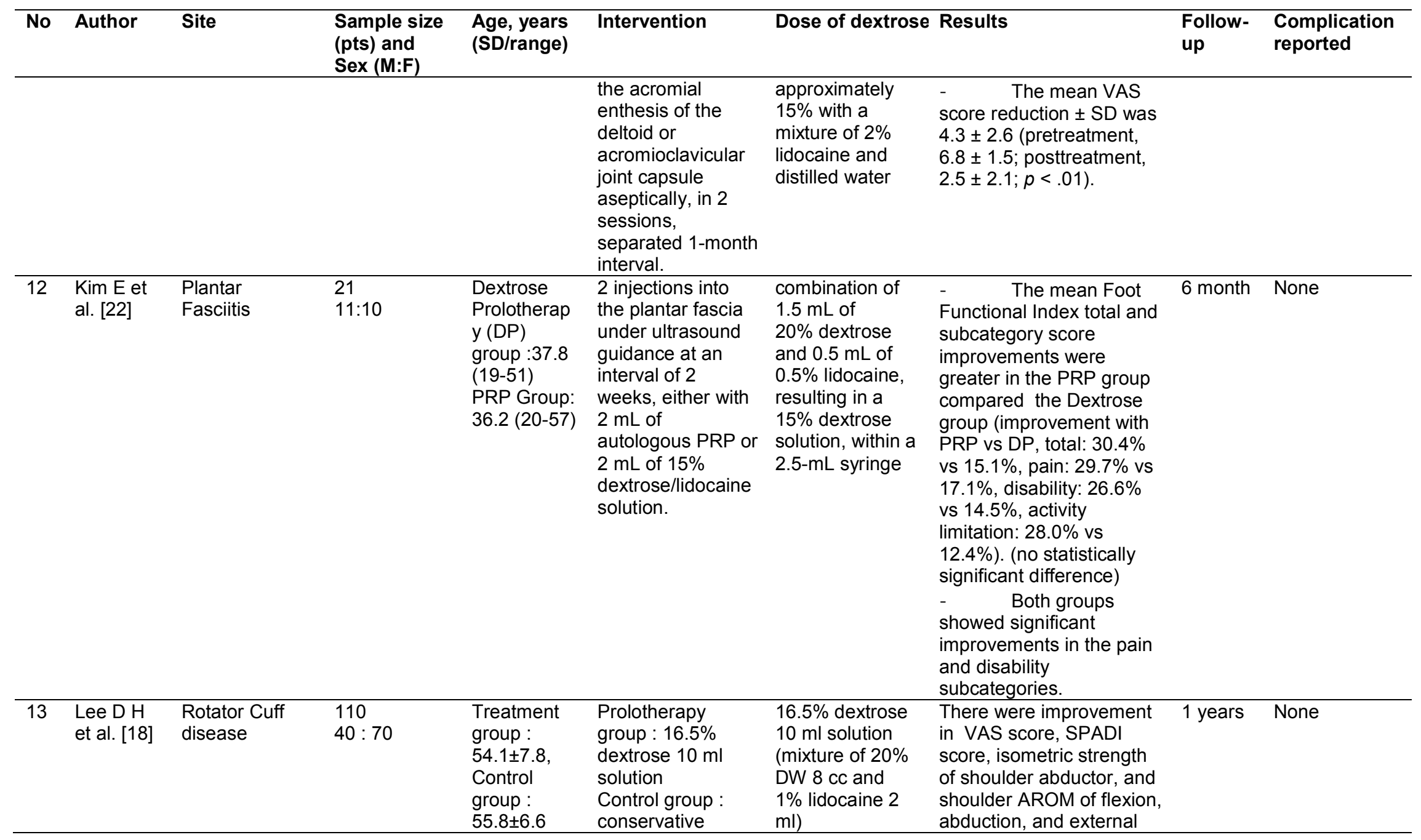


Rhatomy et al.; ARRB, 35(10): 43-62, 2020; Article no.ARRB.61771

\begin{tabular}{|c|c|c|c|c|c|c|c|c|c|}
\hline No & Author & Site & $\begin{array}{l}\text { Sample size } \\
\text { (pts) and } \\
\text { Sex (M:F) }\end{array}$ & $\begin{array}{l}\text { Age, years } \\
\text { (SD/range) }\end{array}$ & Intervention & Dose of dextrose & Results & $\begin{array}{l}\text { Follow- } \\
\text { up }\end{array}$ & $\begin{array}{l}\text { Complication } \\
\text { reported }\end{array}$ \\
\hline & & & & & treatment & & $\begin{array}{l}\text { rotation in the treatment } \\
\text { group. } \\
\text { There were no adverse } \\
\text { events. }\end{array}$ & & \\
\hline \multirow[t]{2}{*}{14} & $\begin{array}{l}\text { Chan O et } \\
\text { al. [23] }\end{array}$ & $\begin{array}{l}\text { Achilles } \\
\text { Tendon }\end{array}$ & $\begin{array}{l}43 \\
27: 16\end{array}$ & $41(11.3)$ & $\begin{array}{l}\text { Injected } \\
\text { with } 0.4 \mathrm{ml}-1.5 \mathrm{ml} \\
\text { (mean } 0.8 \mathrm{ml} \text { ) of } \\
50 \% \text { dextrose } \\
\text { and } 0.5 \% \\
\text { Marcaine mixed in } \\
\text { a } 1: 1 \text { ratio. }\end{array}$ & $\begin{array}{l}0.4 \mathrm{ml}-1.5 \mathrm{ml} \\
\text { (mean } 0.8 \mathrm{ml} \text { ) of } \\
50 \% \text { dextrose } \\
\text { and } 0.5 \% \\
\text { Marcaine mixed } \\
\text { in a } 1: 1 \text { ratio }\end{array}$ & $\begin{array}{l}-\quad 30 \text { patients }(70 \%) \\
\text { responded with VISA-A } \\
\text { scores increasing by } 31 \\
(30.5) \text { points after } 3 \\
\text { months }(p<0.05) \text { and by } \\
40(29.3) \text { points after } \\
12.60(7.0) \text { months } \\
(p<0.05) .\end{array}$ & & $\begin{array}{l}\text { One patient } \\
\text { (with a history } \\
\text { of previous } \\
\text { DVTs) } \\
\text { suffered a } \\
\text { DVT two } \\
\text { weeks after } \\
\text { the injection }\end{array}$ \\
\hline & & & & & & & $\begin{array}{l}\quad \text { After } 5.2(2.3) \\
\text { weeks, echogenicity was } \\
\text { significantly reduced } \\
(p<0.05) \text { and } 27 \% \text { of tears } \\
\text { were no longer detectable. }\end{array}$ & & \\
\hline 15 & $\begin{array}{l}\text { Ryan M et } \\
\text { al. [24] }\end{array}$ & $\begin{array}{l}\text { Patellar } \\
\text { tendinopathy }\end{array}$ & $\begin{array}{l}47 \mathrm{pts}(49 \\
\text { tendon) } \\
39: 6\end{array}$ & NR & $\begin{array}{l}\text { Injection of } 25 \% \\
\text { dextrose with } \\
\text { lidocaine into the } \\
\text { area of } \\
\text { tendinopathy } \\
\text {. }\end{array}$ & $\begin{array}{l}25 \% \text { dextrose }(1 \\
\mathrm{ml} 2 \% \text { lidocaine } \\
(20 \mathrm{mg} / \mathrm{ml}) \text { and } \\
1 \mathrm{ml} 50 \% \\
\text { dextrose }(25 \\
\mathrm{g} / 50 \mathrm{ml}) \\
\text { (dextrose }\end{array}$ & $\begin{array}{l}\text { - Subjects reported } \\
\text { a reduction in pain across } \\
\text { the three VAS items (rest } \\
38.4 \pm 25-18.7 \pm 18.4 ; \text { ADL } \\
51.1 \pm 22.9-25.8 \pm 20.1 ; \\
\text { sport } 78.1 \pm 15.7- \\
38.8 \pm 26.1 ; p<0.01 \text { ). }\end{array}$ & $\begin{array}{l}45 \\
\text { weeks }\end{array}$ & None \\
\hline & & & & & & $\begin{array}{l}\text { monohydrate in } \\
\text { a } 2.5 \mathrm{ml} \text { syringe } \\
500 \mathrm{mg} \text { ) }\end{array}$ & $\begin{array}{l}\quad \text { There was } \\
\text { improvement in } \\
\text { neovascularity following } \\
\text { the dextrose injection. }\end{array}$ & & \\
\hline 16 & $\begin{array}{l}\text { Yelland } \\
\text { MJ et al. } \\
{[29]}\end{array}$ & $\begin{array}{l}\text { Achilles } \\
\text { Trendinosis }\end{array}$ & 43 & $46(40-57)$ & $\begin{array}{l}\text { Participants were } \\
\text { randomised to a } \\
\text { 12-week program } \\
\text { of eccentric } \\
\text { loading exercises } \\
\text { (ELE) }(n=15) \text {, or }\end{array}$ & $\begin{array}{l}20 \% \\
\text { glucose } / 0.1 \% \\
\text { lignocaine } / 0.1 \% \\
\text { ropivacaine } \\
\text { weekly } \\
\text { for four to } 12\end{array}$ & $\begin{array}{l}\text { - At } 12 \text { months: the } \\
\text { minimum clinically } \\
\text { important change }(\mathrm{MCIC}) \\
\text { for VISA-A were } 73 \% \text { for } \\
\text { ELE, } 79 \% \text { for prolotherapy } \\
\text { and } 86 \% \text { for combined }\end{array}$ & $\begin{array}{l}12 \\
\text { Month }\end{array}$ & None \\
\hline
\end{tabular}


Rhatomy et al.; ARRB, 35(10): 43-62, 2020; Article no.ARRB.61771

\begin{tabular}{|c|c|c|c|c|c|c|c|c|c|}
\hline No & Author & Site & $\begin{array}{l}\text { Sample size } \\
\text { (pts) and } \\
\text { Sex (M:F) }\end{array}$ & $\begin{array}{l}\text { Age, years } \\
\text { (SD/range) }\end{array}$ & Intervention & Dose of dextrose & Results & $\begin{array}{l}\text { Follow- } \\
\text { up }\end{array}$ & $\begin{array}{l}\text { Complication } \\
\text { reported }\end{array}$ \\
\hline & & & & & $\begin{array}{l}\text { prolotherapy } \\
\text { injections of } \\
\text { hypertonic glucose } \\
\text { with lignocaine } \\
\text { alongside the } \\
\text { affected tendon } \\
(n=14) \text { or } \\
\text { combined } \\
\text { treatment }(n=14) \text {. }\end{array}$ & treatments & $\begin{array}{l}\text { treatment. } \\
-\quad \text { Mean (95\% CI) } \\
\text { increases in VISA-A } \\
\text { scores at } 12 \text { months were } \\
23.7(15.6 \text { to } 31.9) \text { for } \\
\text { ELE, } 27.5(12.8 \text { to } 42.2) \\
\text { for prolotherapy and } 41.1 \\
(29.3 \text { to } 52.9) \text { for } \\
\text { combined treatment. } \\
-\quad \quad \text { Compared with } \\
\text { ELE, reductions in } \\
\text { stiffness and limitation of } \\
\text { activity occurred earlier } \\
\text { with prolotherapy and } \\
\text { reductions in pain, } \\
\text { stiffness and limitation of } \\
\text { activity occurred earlier } \\
\text { with combined treatment. }\end{array}$ & & \\
\hline 17 & $\begin{array}{l}\text { Reeves } \\
\text { KD et al. } \\
{[25]}\end{array}$ & $\begin{array}{l}\text { Anterior } \\
\text { Cruciate } \\
\text { ligament laxity }\end{array}$ & 18 & 68 & $\begin{array}{l}\text { Intraarticular } \\
\text { injection of } 6-9 \mathrm{cc} \\
\text { of } 10 \% \text { dextrose at } \\
\text { months } 0,2,4,6 \text {, } \\
\text { and } 10 \text {. Injection } \\
\text { with } 6 \mathrm{cc} \text { of } 25 \% \\
\text { dextrose at } 12 \\
\text { months. } \\
\text { Then, depending } \\
\text { on patient } \\
\text { preference, } \\
\text { injection of either } \\
10 \% \text { or } 25 \% \\
\text { dextrose } \\
\text { every } 2-4 \text { months } \\
\text { (based on patient }\end{array}$ & $\begin{array}{l}10 \% \text { dextrose } \\
\text { and } \\
25 \% \text { dextrose }\end{array}$ & $\begin{array}{l}\text { - KT1000 } \\
\text { measurement : } 6 \text { knees } \\
\text { measured as normal (not } \\
\text { loose) after } 6 \text { months, } 9 \\
\text { measured as normal after } \\
1 \text { year ( } 6 \text { injections), and } \\
10 \text { measured as normal at } \\
3 \text { years. } \\
-\quad 3 \text { year follow-up, } \\
\text { pain at rest, pain with } \\
\text { walking, and pain with } \\
\text { stair use had improved } \\
-\quad \text { Individual paired } t \\
\text { tests indicated subjective } \\
\text { swelling improved } 63 \% \text { ( } p \\
=.017) \text {, flexion range of }\end{array}$ & $\begin{array}{l}36 \\
\text { month }\end{array}$ & $\begin{array}{l}\text { Discomfort } \\
\text { after injection }\end{array}$ \\
\hline
\end{tabular}


Rhatomy et al.; ARRB, 35(10): 43-62, 2020; Article no.ARRB.61771

\begin{tabular}{|c|c|c|c|c|c|c|c|c|}
\hline No & Author & Site & $\begin{array}{l}\text { Sample size } \\
\text { (pts) and } \\
\text { Sex (M:F) }\end{array}$ & $\begin{array}{l}\text { Age, years } \\
\text { (SD/range) }\end{array}$ & Intervention & Dose of dextrose Results & $\begin{array}{l}\text { Follow- } \\
\text { up }\end{array}$ & $\begin{array}{l}\text { Complication } \\
\text { reported }\end{array}$ \\
\hline & & & & & $\begin{array}{l}\text { preference) } \\
\text { through } 36 \\
\text { months. }\end{array}$ & $\begin{array}{l}\text { motion improved by } 10.5 \\
\text { degrees }(p=.002) \text {, and } \\
\text { KT1000 ADD improved by } \\
71 \%(p=.002) .\end{array}$ & & \\
\hline
\end{tabular}

VISA A: The Victorian Institute of Sport Assessment-Achilles questionnaire, PRP: Platelet Rich plasma

Table 3. Animal studies results

\begin{tabular}{|c|c|c|c|c|c|}
\hline Author & Animal & Site & Intervention & $\begin{array}{l}\text { Dose of } \\
\text { dextrose }\end{array}$ & Outcomes \\
\hline $\begin{array}{l}\text { Jensen, K T et al. } \\
{[30]}\end{array}$ & Rat & $\begin{array}{l}\text { Medial Collateral } \\
\text { Ligament }\end{array}$ & $\begin{array}{l}\text { - MCL of } 84 \text { Sprague- Dawley rats } \\
\text { were injected one time at both the } \\
\text { tibial and femoral insertions. } \\
\text { - IHC to determine the inflammatory } \\
\text { response at three locations (tibial } \\
\text { and femoral insertions and } \\
\text { midsubstance) } 6,24 \text {, and } 72 \mathrm{~h} \text { after } \\
\text { dextrose injection compared to } \\
\text { saline- and no-injection controls } \\
\text { and collagenase (positive control) } \\
\text { - qPCR was used to analyze gene } \\
\text { expression }\end{array}$ & $\begin{array}{l}15 \% \\
\text { Dextrose }\end{array}$ & $\begin{array}{l}\text { - Inflammation (CD43) increased after prolotherapy } \\
\text { injection compared to no-injection control but did not } \\
\text { increase consistently compared to saline and } \\
\text { needlestick control injections. } \\
\text { - This response varied by both location and proliferant. } \\
\text { - Inflammation was observed at } 6 \text { and } 24 \text { h post-injection } \\
\text { but was resolved by } 72 \text { h compared to no-injection } \\
\text { controls }(p<0.05) \text {. } \\
\text { - Prolotherapy injections created an inflammatory } \\
\text { response, the response was variable and overall, not } \\
\text { uniformly different from that caused by saline injections } \\
\text { or needlestick procedures }\end{array}$ \\
\hline $\begin{array}{l}\text { Jensen, KT et al. } \\
\text { [27] }\end{array}$ & Rat & $\begin{array}{l}\text { Medial Collateral } \\
\text { Ligament }\end{array}$ & $\begin{array}{l}\text { Twenty-four rats were bilaterally MCL } \\
\text { stretch-injured, and the induced laxity } \\
\text { was measured. After } 2 \text { weeks, } 32 \\
\text { MCLs } \\
\text { were injected twice, } 1 \text { week apart, } \\
\text { with either dextrose or saline control; } \\
16 \text { MCLs received no injection. Seven } \\
\text { uninjured rats ( } 14 \text { MCLs) were } \\
\text { additional controls. } \\
\text { Two weeks after the second injection, } \\
\text { ligament laxity, mechanical properties }\end{array}$ & $\begin{array}{l}15 \% \\
\text { Dextrose }\end{array}$ & $\begin{array}{l}\text { - Cross-sectional area of dextrose-injected MCLs was } \\
\text { increased } 30 \% \text { and } 90 \% \text { compared with saline and } \\
\text { uninjured controls, respectively }(p<.05) \text {. } \\
\text { - Collagen fibril diameter and density were decreased in } \\
\text { injured ligaments compared with uninjured controls }(p< \\
\text {.05), but collagen fibril characteristics were not different } \\
\text { between injured groups. }\end{array}$ \\
\hline
\end{tabular}


Rhatomy et al.; ARRB, 35(10): 43-62, 2020; Article no.ARRB.61771

\begin{tabular}{|c|c|c|c|c|c|}
\hline Author & Animal & Site & Intervention & $\begin{array}{l}\text { Dose of } \\
\text { dextrose }\end{array}$ & Outcomes \\
\hline & & & $\begin{array}{l}(n=8), \text { and collagen } \\
\text { fibril diameter and density }(n=3) \\
\text { were assessed. }\end{array}$ & & \\
\hline Martins et al. [31] & Rat & Achilles Tendon & $\begin{array}{l}15 \text { received } 12.5 \% \text { dextrose (group I); } \\
15 \text { were treated with } \\
\text { corticosteroid injection (group II); and } \\
15 \text { were given } 0.9 \% \\
\text { saline injection (group III), all into the } \\
\text { right Achilles tendon, } \\
\text { whereas } 13 \text { animals received no } \\
\text { injections (group IV). } \\
\text { Three doses of each substance } \\
\text { (groups I, II, and III) were } \\
\text { given at a 5-day interval. Collagen } \\
\text { fiber color was quantitatively } \\
\text { assessed in three samples from each } \\
\text { group and in } \\
\text { five samples from the control group } \\
\text { using picrosirius red } \\
\text { staining under polarized and } \\
\text { nonpolarized light. }\end{array}$ & $\begin{array}{l}12.5 \% \\
\text { dextrose }\end{array}$ & $\begin{array}{l}\text { - There was no statistical difference across the groups } \\
\text { with respect to maximum load at failure (n.s.) and } \\
\text { absorbed energy (n.s.). With respect to tendon rupture, } \\
\text { - there was no difference between the myotendinous } \\
\text { and the tendinous regions (n.s.). } \\
\text { - Hematoxylin-eosin staining revealed statistical } \\
\text { significance in lymphocytic inflammatory infiltrate }(p= \\
\text { 0.008) and in parallel fiber orientation }(p=0.003) \text { when } \\
\text { comparing groups to the control group, without } \\
\text { significance for either neovascularization (n.s.) or the } \\
\text { presence of fibroblasts (n.s.). } \\
\text { - There was no significant difference between the } \\
\text { percentage of mature (n.s.) and immature (n.s.) fibers }\end{array}$ \\
\hline Tsai SW et al. [26] & Rat & $\begin{array}{l}\text { Gastrocnemius } \\
\text { Muscle }\end{array}$ & $\begin{array}{l}\text { Mice were separated into five } \\
\text { groups, including a normal control } \\
\text { (NC), post-injury with no treatment } \\
\text { (mass-drop injury, MDI), } \\
\text { post-injury with } 10 \% \text { dextrose (MDI + } \\
10 \% \text { dextrose), post-injury with } 20 \% \\
\text { dextrose (MDI + } 20 \% \\
\text { dextrose), and post-injury with } 30 \% \\
\text { dextrose (MDI + } 30 \% \text { dextrose). The } \\
\text { gastrocnemius muscles of the } \\
\text { mice were subjected to an MDI, and } \\
\text { muscle samples were collected at } 7 \\
\text { days post-injury. }\end{array}$ & $\begin{array}{l}10 \%, 20 \% \\
\text { and } 30 \% \\
\text { Dextrose }\end{array}$ & $\begin{array}{l}\text { - The serum creatine kinase (CK), blood urea nitrogen } \\
\text { (BUN), creatinine (CREA), and low-density lipoprotein } \\
\text { (LDH) of the MDI-alone group were significantly higher } \\
\text { than those of the normal control group }(p<0.05) \text {. } \\
\text { - However, levels of serum CK, BUN, CREA, and lactate } \\
\text { dehydrogenase (LDH) significantly decreased with } \\
\text { different concentrations of dextrose. } \\
\text { - Dextrose suppressed the macrophage response (F4/80 } \\
\text { protein decreased) and promoted muscle satellite cell } \\
\text { regeneration (desmin protein increased). }\end{array}$ \\
\hline
\end{tabular}


Table 4. In vitro studies results

\begin{tabular}{|c|c|c|c|c|c|}
\hline Author & Subject & Studied Cells & Intervention & Dose of dextrose & Outcomes \\
\hline $\begin{array}{l}\text { Freeman JW et al. } \\
\text { [32] }\end{array}$ & Rat & $\begin{array}{l}\text { Mouse } \\
\text { preosteoblast } \\
\text { cells (MC3T3- } \\
\text { E1 cells) and } \\
\text { mouse patellar } \\
\text { tendon } \\
\text { fibroblasts }\end{array}$ & $\begin{array}{l}\text { P2G } \\
\text { was administered } \\
\text { to mouse preosteoblast cells (MC3T3- } \\
\text { E1, } \\
\text { ATCC, Manassas, Va) in various } \\
\text { dosages }\end{array}$ & $\begin{array}{l}\text { P2G is a solution } \\
\text { composed of } 2 \% \\
\text { phenol, } 25 \% \\
\text { dextrose, and } \\
25 \% \text { glycerin in a } \\
\text { sufficient quantity } \\
\text { of sterile water for } \\
\text { injection }\end{array}$ & $\begin{array}{l}\text { - Trichrome staining : an increasing in collagen } \\
\text { production } \\
\text { - The cell numbers and amounts of collagen from } \\
\text { the treated groups never surpassed those of the } \\
\text { untreated groups, although collagen production } \\
\text { was comparable in fibroblasts. } \\
\text { - There is an effective proliferant dosage and } \\
\text { point to a local response to the proliferant that } \\
\text { increases cell proliferation and collagen } \\
\text { production. }\end{array}$ \\
\hline $\begin{array}{l}\text { Şefik Güran et al } \\
\text { [33] }\end{array}$ & Human & $\begin{array}{l}\text { Adult human } \\
\text { fibroblasts }\end{array}$ & $\begin{array}{l}\text { The effects of dextrose solution ( } 1 \% \text {, } \\
5 \%, 10 \% \text {-low doses, } 15 \%, 20 \% \text { and } \\
25 \% \text {-high doses) in vitro, using human } \\
\text { fibroblast culture. } \\
\text { Total RNA extraction and cDNA } \\
\text { synthesis were performed. } \\
\text { The gene expression levels of } \\
\text { angiogenic and apoptotic factors were } \\
\text { analyzed by using real-time PCR. }\end{array}$ & $\begin{array}{l}1 \%, 5 \%, 10 \% \text {-low } \\
\text { doses, } 15 \%, 20 \% \\
\text { and } 25 \% \text {-high } \\
\text { doses) }\end{array}$ & $\begin{array}{l}\text { - High doses dextrose concentrations, up to } 80 \% \\
\text { of fibroblasts were died because of toxic } \\
\text { conditions. } \\
\text { - Viable fibroblast cell ratios were decreased } \\
\text { proportionally due to the dextrose concentration. } \\
\text { - Low dextrose concentrations increased gene } \\
\text { expressions in angiogenic (VEGF A, PDGFA, } \\
\text { PDGF B, IGF 1) and in apoptotic factors } \\
\text { (CASP3 and CASP8) in fibroblasts. }\end{array}$ \\
\hline $\begin{array}{l}\text { Ekwueme EC et al. } \\
{[34]}\end{array}$ & Human & $\begin{array}{l}\text { Human } \\
\text { hamstring and } \\
\text { Achilles tendon } \\
\text { Cells }\end{array}$ & $\begin{array}{l}\text { - Assess the effect of dextrose and } \\
\text { P2G proliferant treatment on cell } \\
\text { mitochondrial activity compared with } \\
\text { nontreated tenocytes. } \\
\text { - Quantitative PCR, ELISA, and a } \\
\text { reporter cell line assessed the } \\
\text { expression of several key markers } \\
\text { involved in tendon development and } \\
\text { inflammation. }\end{array}$ & $50 \%(v / v)$ dextrose & $\begin{array}{l}\text { - Decreasing of tenocyte metabolic activity, P2G } \\
\text { more pronounced effect }(75 \% \pm 7 \% \text { versus } 95 \% \\
\pm 7 \% \text { of untreated control cell metabolic levels) } \\
\text { - Gene expression: upregulation of key } \\
\text { proinflammatory markers; IL-8 and } \\
\text { cyclooxygenase-2 and downregulation of } \\
\text { collagen type I. } \\
\text { - A reporter cell line : decreasing of TGF-b } \\
\text { bioactivity. } \\
\text { - ELISA : elevated PGE2 }\end{array}$ \\
\hline
\end{tabular}

PGE2: prostaglandin E2, VEGF: Vascular Endothelial Growth Factor, PDGF: Platelet-derived Growth Factor, IGF: Insulin-like Growth Factor, CASP: Caspase 


\subsection{Complications / Adverse Effects}

Only four studies reported adverse effects after dextrose prolotherapy and all of the adverse effects were minor effects, such as discomfort [8], minor soreness [8], extreme pain [9], skin burns grade 2nd because of improper use of hot water bags and local anaesthetic effect of the injections [9], hypotension [9] and Deep Vein Thrombosis (DVT), in a patient who has a history of DVT [28].

\section{DISCUSSION}

This review suggests that dextrose prolotherapy for treatment of muscle, ligament and tendon tear or pathology, demonstrates potential results in decreasing pain, improving range of motion, and function outcomes, at least in the short term follow-up, and increasing of cell proliferation and neovascularization in in vitro study. Single or serial injections of dextrose showed improvements of clinical outcomes and may be a promising treatment for long term follow-up. High quality of research is needed with specific populations with soft tissue problems (tendon, ligament and muscle) to determine the best protocol for treatment of soft tissue problem including time interval of injections, volume, concentration of dextrose solution, and location of injection.

Prolotherapy for musculoskeletal pain has been used in practice as an adjuvant treatment for decades [5]. Thus, in this review, we found that most of studies were clinical studies (70.8\%), which indicated this treatment has been used for many years, and most of clinical studies involved supraspinatus tendinopathy or tearing and Achilles tendinopathy. Tendinopathy of the supraspinatus and Achilles tendon is a common problem in adult patients and often is the cause of pain that disturbs their daily activity. This is caused by overuse and repetitive loads on the tendon, such as in sports activity $[9,12,18]$.

The main purpose of dextrose prolotherapy treatment is to decrease of pain and improve functional outcomes [9]. In our study, all of the studies reported decreased pain after treatment and most of studies (eleven studies) reported functional improvement after follow up. Reduction in pain is closely related to improvements in the functional clinical outcome. By significantly reducing pain, it will help physiotherapy programs and at the same time improve patients' functional outcome. Cole et al. showed that injection of dextrose prolotherapy for the supraspinatus tendon can reduce pain and improve functional outcome over a 6-month period. There was no adverse effects on tendon structure and, in fact, prolotherapy groups showed significant improvements in ultrasound characteristics of the supraspinatus tendon, decreasing pain, with increased range of motion and strength of muscle [32].

In previous review study, dextrose prolotherapy improved patient satisfaction in as many as $82 \%$ of cases in treating knee osteoarthritis [33]. In our study, there were two studies that evaluated patient satisfaction. Lyftogt et al. reported that fourteen patients $(29.1 \%)$ were satisfied and can return to pre-injury levels of activity [15].

Most of the studies on dextrose prolotherapy for musculoskeletal conditions, were for chronic, painful overused tendon conditions. Despite different anatomical locations, the tendinopathies of repetitive and overuse injuries have similar characteristics. The process of tendinopathy of the Achilles tendon, common elbow extensors and patellar tendons have almost the same histological, sonographic and clinical features. The main role of dextrose prolotherapy is to reduce pain significantly, so that the patient can undergo physiotherapy optimally and improve their functional ability and range of motion [5]. In our review, there were three studies that reported increased neovascularization, collagenization, and cell proliferation after treatment $[16,17,22]$.

In vitro studies on human fibroblasts and chondrocytes using extracellular $0.5 \%$ dextrose showed that there were increasing of cell proliferation and production of numerous growth factors, such as platelet-derived growth factor, transforming growth factor $\beta$, epidermal growth factor, basic fibroblast growth factor, insulin-like growth factor and connective tissue growth factor. These growth factors have important role for regeneration and structural integrity of tendons, ligaments, and muscles [5,27]. One in vitro study showed that these growth factors can promote the prominent expression of types 1 and 3 collagen in tenocytes and prevent fibrous tissue. These mechanism could be an inexpensive method of soft tissue regeneration, and that may be more cost effective and promising for the long term follow-up [5,27].

In clinical settings, many studies showed that dextrose concentrations higher than $10 \%$ can enhance the inflammatory process, while 
concentrations less than $10 \%$ are considered noninflammatory [5]. In this review, there were three studies that showed the similar effect of increasing inflammatory response after treatment with $15 \%, 30 \%$, and $50 \%$ of dextrose [25,26,29]. Other outcomes were reported by Freeman et al. that explained there are increasing cell proliferation and collagen production after dextrose treatment [27].

In this review, dextrose concentrations that were more often used to treat soft tissue problems were $15 \%, 20 \%$ and $25 \%$ and most of them were mixed with lidocaine and performed as a single injection. This is similar with previous review that evaluated dextrose prolotherapy for musculoskeletal pain, and found that the most common prolotherapy agent used in clinical practice is dextrose, with concentrations ranging from $12.5 \%$ to $25 \%$ [5].

Few adverse effects or complications after prolotherapy have been reported in the previous studies. Simon et al. reported adverse events related to prolotherapy for back and neck pain, such as temporary post injection pain, stiffness, and bruising [34]. In this review, we found that only four studies reported adverse effects after dextrose prolotherapy, and all of the adverse effects were minor effects, such as discomfort [8], minor soreness [8], extreme pain for one or two days [9], grade $2^{\text {nd }}$ skin burns because of improper use of hot water bags and local anaesthetic effect [9], while the other reported adverse effects were hypotension [9], and Deep Vein Thrombosis/DVT in a patient with a history of DVT [28].

\section{CONCLUSION}

Dextrose prolotherapy is a potentially effective treatment for patients with muscle, tendon or ligament tear or pathology. Efficacy in long term follow-up, as single therapy or first-line therapy, and long term outcomes cannot be determined from the current literature.

\section{ACKNOWLEDGEMENT}

We thank Erik Christopher with his help during manuscript preparation.

\section{COMPETING INTERESTS}

Authors have declared that no competing interests exist.

\section{REFERENCES}

1. Woolf AD, Pfleger B. Burden of major musculoskeletal conditions. Bull World Heal Organ. 2003;81:646-656.

2. Hootman JM, Macera CA, Ainsworth BE, Addy CL, Martin M, Blair SN. Epidemiology of musculoskeletal injuries among sedentary and physically active adults. Med Sci Sport Exerc. 2002;34:838-44.

3. Shah $R$, Sinclair A. Utilization of prolotherapy for facilitation of ligament and tendon healing. Athl Ther Today. 2010;15(11):25-7.

4. Yelland MJ, Mar C. Del, Pirozzo S, Schoene ML. Prolotherapy injections for chronic low back pain: A systematic review. Spine (Phila $\mathrm{Pa}$ 1976). 2004;29(19):2126-33.

5. Hauser RA, Lackner JB, Steilen-matias D, Harris DK. A systematic review of dextrose prolotherapy for chronic musculoskeletal pain. Clin Med Insights Arthritis Musculoskelet Disord. 2016;9:139-59.

6. Moher D, Liberati A, Tetzlaff J, Altman DG. Preferred reporting items for systematic reviews and meta-analyses: The PRISMA statement. BMJ. 2009;339(7716):332-6.

7. Longo UG, Rizzello G, Loppini M, Locher J, Buchmann S, Maffulli $\mathrm{N}$, et al. Multidirectional instability of the shoulder: A systematic review. Arthrosc - J Arthrosc Relat Surg. 2015;31(12):2431-43.

8. Bertrand $\mathrm{H}$, Reeves KD, Bennett J, Bicknell S, Cheng A, Statistics PD. Dextrose prolotherapy versus control injections in painful rotator cuff tendinopathy. Arch Phys Med Rehabil. 2016;97:17-25.

9. Seven MM, Ersen O, Akpancar S, Ozkan $\mathrm{H}$, Turkkan S, Yıldız Y, et al. Effectiveness of prolotherapy in the treatment of chronic rotator cuff lesions. Orthop Traumatol Surg Res [Internet]. 2017;103(3):427-33.

Available:http://dx.doi.org/10.1016/j.otsr.20 17.01.003

10. George J, Li SC, Jaafar ZHM. Comparative effectiveness of ultrasound-guided intratendinous prolotherapy injection with conventional treatment to treat focal supraspinatus tendinosis. Sci. 2018;1-6.

11. Lin C, Huang C, Huang S. Effects of hypertonic dextrose injection on chronic supraspinatus tendinopathy of the shoulder: Randomized effects placebo- 
controlled trial. Eur J Phys Rehabil Med. 2018;55(4):480-7.

12. Cole B, Lam P, Hackett L, Murrell GAC. Ultrasound-guided injections for supraspinatus tendinopathy: Corticosteroid versus glucose prolotherapy - a randomized controlled clinical trial. Shoulder Elb. 2017;1-9.

13. Lee D, Kwack K, Rah UW, Yoon S. Prolotherapy for refractory rotator cuff disease: Retrospective case-control study of one year follow-up. Arch Phys Med Rehabil. 2015;96(11):2027-32.

14. Buchanan BK, Deluca JP, Lammlein KP. Case report technical innovation case report: Ultrasound-guided prolotherapy injection for insertional Achilles calcific tendinosis. Case Rep Orthop. 2016;15.

15. Lyftogt J, Zealand N. Prolotherapy and Achilles tendinopathy: A prospective pilot study of an old treatment. Australas Musculoskelet Med. 2005;10(1):16-9.

16. Maxwell NJ, Ryan MB, Taunton JE, Gillies $\mathrm{JH}$, Wong $\mathrm{AD}, \mathrm{Nj} \mathrm{M}$, et al. Intratendinous injection of hyperosmolar dextrose to treat chronic tendinosis of the Achilles tendon: A pilot study. AJR. 2007;189(10):21520.

17. Ryan M, Wong A, Taunton J. Favorable outcomes after sonographically guided intratendinous injection of hyperosmolar dextrose for chronic insertional and midportion Achilles tendinosis. AJR. 2010;194(4):1047-53.

18. Yelland MJ, Sweeting KR, Lyftogt JA, Ng SK, Scuffham PA, Evans KA. Prolotherapy injections and eccentric loading exercises for painful Achilles tendinosis: A randomised trial. $\mathrm{Br} J$ Sport Med. 2011;45(5):421-8.

19. Fullerton BD. High-resolution ultrasound and magnetic resonance imaging to document tissue repair after prolotherapy: A report of 3 cases. Arch Phys Med Rehabil. 2008;89:377-85.

20. Pei-Chun Hsieh, Hong-Jen Chiou, Hsin-Kai Wang, Yi-Chen Lai, Yung-Hui Lin M. Ultrasound-guided prolotherapy for acromial enthesopathy and acromioclavicular joint arthropathy: A single-arm prospective study. J Ultrasound Med. 2018;1-8.

21. Kim E, Lee JH. Autologous platelet-rich plasma versus dextrose prolotherapy for the treatment of chronic recalcitrant plantar fasciitis. PM R. 2014;6(2):152-8.
22. Ryan $M$, Wong $A$, Rabago $D$, Lee $K$, Taunton J. Ultrasound-guided injections of hyperosmolar dextrose for overuse patellar tendinopathy: A pilot study. $\mathrm{Br} \mathrm{J}$ Sports Med. 2011;45(12):972-7.

23. Reeves KD, Hassanein KM. Long term effects of dextrose ligament laxity. Altern Ther. 2003;9(3):58-62.

24. Jensen KT, Rabago DP, Best TM, Patterson JJ, Jr RV. Response of knee ligaments to prolotherapy in a rat injury model. Am J Sports Med. 2008;36(7): 1347-57.

25. Martins CAQ, Bertuzzi RT, Tisot RA, Michelin AF, Stroher A, Burigo M. Dextrose prolotherapy and corticosteroid injection into rat Achilles tendon. Knee Surg Sport Traumatol Arthrosc. 2012;20:1895-900.

26. Ekwueme EC, Mohiuddin M, Yarborough JA, Brolinson PG, Docheva D, Fernandes HAM, et al. Prolotherapy induces an inflammatory response in human tenocytes in vitro. Clin Orthop Relat Res. 2017;475(8):2117-27.

27. Freeman JW, Empson YM, Ekwueme EC, Paynter DM, Brolinson PG. Effect of prolotherapy on cellular proliferation. Transl Res. 2011;158(0298):132-9.

28. Chan O, Havard B, Morton S, Pritchard M, Maffulli N, Crisp $T$, et al. Outcomes of prolotherapy for intra-tendinous Achilles tears: A case series. Muscles Ligaments Tendons J. 2017;7(1):78-87.

29. Jensen KT, Rabago DP, Best TM, Patterson JJ, Jr RV. Early inflammatory response of knee ligaments to prolotherapy in a rat model. J Orthop Res. 2008;26(6):816-23.

30. Tsai S, Hsu Y, Lee M, Huang H, Huang C, Tung $Y$. Effects of dextrose prolotherapy on contusion-induced muscle injuries in mice. Int J Med Sci. 2018;15(11):1251-9.

31. Güran Ş, Çoban ZD, Karasimav Ö, Demirhan S, Karaağaç $N$, Örsçelik A. Dextrose solution used for prolotherapy decreases cell viability and increases gene expressions of angiogenic and apopitotic factors. Gulhane Med J. 2018;60:42-6.

32. Catapano M, Zhang K, Mittal N, Sangha $H$, Onishi K, Sa D. De. Effectiveness of dextrose prolotherapy for rotator cuff tendinopathy: A systematic review. PMR. 2020;12:288-300.

33. Hassan F, Trebinjac S, Murrell WD. The effectiveness of prolotherapy in treating knee osteoarthritis in adults a systematic review. Br Med Bull. 2017;122(1):91-108. 
34. Wooley JR, Newcomb RL, SAD, Ogunseitan O, Haldeman S. Side effects and adverse events related to intraligamentous injection of sclerosing solutions (Prolotherapy) for back and neck pain: A survey of practitioners. Arch Phys Med Rehabil. 2006;87(7):90913.

(c) 2020 Rhatomy et al.; This is an Open Access article distributed under the terms of the Creative Commons Attribution License (http://creativecommons.org/licenses/by/4.0), which permits unrestricted use, distribution, and reproduction in any medium, provided the original work is properly cited.

Peer-review history:

The peer review history for this paper can be accessed here: http://www.sdiarticle4.com/review-history/61771 